\title{
Ecosystem service delivery in Karst landscapes: anthropogenic perturbation and recovery
}

\author{
Timothy Quine ${ }^{1} \cdot$ Dali Guo ${ }^{2} \cdot$ Sophie M. Green ${ }^{1} \cdot$ Chenglong $\mathbf{T u}^{3}$. \\ Iain Hartley ${ }^{1}$ Xinyu Zhang ${ }^{2}$ Jennifer Dungait ${ }^{4}$ Xuefa Wen $^{2} \cdot$ Zhaoliang Song $^{5}$. \\ Hongyan Liu ${ }^{6} \cdot$ Heather Buss $^{7} \cdot$ Timothy Barrows $^{1} \cdot$ Richard Evershed $^{8}$. \\ Penny Johnes ${ }^{9} \cdot$ Jeroen Meersmans $^{10}$
}

Received: 9 May 2017/Revised: 10 May 2017/Accepted: 10 May 2017/Published online: 9 June 2017

(c) The Author(s) 2017. This article is an open access publication

\begin{abstract}
Covering extensive parts of China, Karst landscapes are exceptional because rapid and intensive land use change has caused severe ecosystem degradation within only the last 50 years. The twentieth century intensification in food production through agriculture has led to a rapid deterioration of soil quality, evidenced in reduced crop production and rapid loss of soil. In many areas, a tipping point appears to have been passed as basement rock is exposed and 'rocky desertification' dominates. Through the establishment of the "Soil processes and ecological services in the karst critical zone of SW China" (SPECTRA) Critical Zone Observatory (CZO) we will endevaour to understand the fundmental processes involved in soil production and erosion, and investigate the integrated geophysical-geochemical-ecological responses of the $\mathrm{CZ}$ to perturbations. The $\mathrm{CZ}$ spans a gradient from undisturbed natural vegetation through human perturbed landscapes. We seek to understand the importance of heterogeneity in
\end{abstract}

11th International Symposium on Geochemistry of the Earth's Surface.

Timothy Quine

T.A.Quine@exeter.ac.uk

1 Geography, College of Life and Environmental Sciences, University of Exeter, Rennes Drive, Exeter EX4 4RJ, UK

2 Institute of Geographic Sciences and Natural Resources Research, Chinese Academy of Sciences, Beijing 100101, People's Republic of China

3 State Key Laboratory of Environmental Geochemistry, Institute of Geochemistry, Chinese Academy of Sciences, Guiyang 550081, Guizhou Province, People's Republic of China

4 Rothamsted Research - North Wyke, Okehampton, Devon EX20 2SB, UK surface and below-ground morphology and flow pathways in determining the spatial distribution of key stocks (soil, $\mathrm{C}$, vegetation, etc.) and their control on ecosystem service delivery. We will assess the extent to which the highly heterogeneous critical zone resources can be restored to enable sustainable delivery of ecosystem services. This paper presents the CZO design and initial assessment of soil and soil organic carbon stocks and evidence for their stability based on caesium-137 $\left({ }^{137} \mathrm{Cs}\right)$ data.

Keywords Soil degradation - Ecosystem services · Caesium-137 · Karst, China

\section{Introduction}

The twentieth century was marked by unprecedented global population growth and associated increase in pressure on land resources for food and fibre production and, in the latter part of the century for energy. Increased pressure on land resources has often resulted in highly accelerated soil loss

5 Institute of the Surface-Earth System Science Research, Tianjin University, Tianjin 300072, People's Republic of China

6 College of Urban and Environmental Sciences, Peking University, Beijing 100871, People's Republic of China

7 School of Earth Sciences, Wills Memorial Building, Queens Road, Clifton BS8 1RJ, UK

8 School of Chemistry, University of Bristol, Cantock's Close, Clifton, Bristol BS8 1TS, UK

9 School of Geographical Sciences, University of Bristol, University Road, Clifton, Bristol BS8 1SS, UK

10 Cranfield Soil and Agrifood Institute, Cranfield University, Cranfield, Bedfordshire MK43 0AL, UK 
and the risk this poses to sustainable use of finite resources has been widely reported (cf Montgomery 2007). At the turn of the century, there was concern that the world population was reaching a 'Malthusian Precipice'; however, this precipice has not yet been reached. In large part this reflects the effectiveness of technical advances in agricultural practice; however, there is also some evidence that ecosystem service delivery may be more resilient than has been feared. For example, where intensive agriculture has been practiced on unconsolidated parent material, there has been in effect an acceleration of soil formation and, although highly eroded soils in these landscapes contain high subsoil content, there is some evidence that soil organic carbon (SOC) stocks can be held in equilibrium by new SOC formation ( $\mathrm{Li}$ et al. 2015). Under these circumstances, SOC respiration rates are suppressed by low SOC content; and, some eroded SOC is replaced by new organic matter; if eroded SOC is conserved, there is potential for an erosion-induced net atmospheric sink for $\mathrm{CO}_{2}$ (Van Oost et al. 2007; Li et al. 2015). Despite this, soil erosion in these relatively favourable environments results in the formation of a highly heterogeneous soil-scape and in the preferential loss of the most biologically active surface with significant impacts on soil properties (Heckrath et al. 2005). Therefore, in many agricultural systems, human perturbation of the food production ecosystem service is lower than feared and the systems appear to have greater resilience than expected. Nevertheless, there is a clear need to develop a quantitative understanding of ecosystem resilience and the potential for recovery in both natural and agricultural ecosystems subject to human perturbation. In this context, Karst landscapes are of particular interest because their high resistance to physical disaggregation may limit the potential to accelerate soil formation. It can, therefore, be argued that karst landscapes represent an endmember on the spectrum of sensitivity of ecosystems to human perturbation in which unsustainable land use can cause catastrophic change in ecosystem function from which the systems may not recover on timescales relevant to land management decision-making.

There is compelling evidence from the Karst landscapes of southern China that the exceptional nature of karst, in particular the low soil formation rates, make these ecosystem vulnerable to severe system degradation. In the natural state, key Ecosystem Services (ES) delivered by these landscapes include carbon (C) storage in soils and biomass; biodiversity; regulation of the hydrological cycle; and aesthetic and cultural services. These ecosystem services are under threat due to twentieth century intensification in food production through agriculture that has led to a rapid deterioration, evidenced in reduced crop production and rapid loss of soil. In many areas, a tipping point appears to have been passed as basement rock is exposed and 'rocky desertification' dominates (Wang et al.
2004, 2014). Indeed, the rapid increase of the rates of rocky desertification is comparable to those of the sandy loess soils in N China (Huang and Cai 2007; Gao et al. 2013).

While, rocky desertification is evidenced in the exposure of basement rock as soil is lost at rates far in excess of replacement (Wang et al. 2004) there is a pressing need to better understand and quantify the changes that occur in soil quality and ecosystem function before this extreme state is reached. It is suggested that the resistance of the parent material to physical breakdown and the low rates of production of soil material by weathering prevent these processes from operating and surface erosion leads to loss of soil depth, loss of nutrients locked up in OM (including microbial biomass; Turner et al. 2013) and reduction in soil structural stability (Le Bissonnais and Arrouays 1997); the latter increases susceptibility to erosion by water. The reduced soil depth and reduced SOM content of the eroded soils leads to significantly lower water holding capacity and maintenance of production under heightened moisture stress is at risk. Furthermore, the ongoing desertification has been suggested to have implications beyond the study region, through changes in evaporation which could affect the timing and location on Monsoon rains in SW China (Gao et al. 2013). The soil degradation not only puts delivery of food provision at risk but also the potential for recovery of ES delivered in the natural state even if agriculture is halted.

The overarching hypotheses that we will address at the SPECTRA CZO are as follows:

1. The thin, nutrient-poor soils which develop in karst landscapes constrain total plant productivity. We hypothesise that the low concentration of rock-derived nutrients in carbonate soils represent the key control on plant productivity, and plant adaptations for alleviating nutrient limitation are key to maintaining the productivity of natural ecosystems.

2. The distribution of silicate minerals within the carbonate rocks plays a key role in controlling ecosystem productivity. There is variation in the presence of small areas of silicate rocks and silicate contamination of carbonate rocks. We hypothesise that the presence of these silicate rocks is critical to soil formation and ecosystem productivity.

3. Along the degradation gradient, there is a tipping point in total soil storage and soil carrying capacity, below which biological activity becomes so low that $\mathrm{CZ}$ function becomes unrecoverable on decadal timescales. As biological activity declines with ecosystem degradation we hypothesise that there is a point beyond which key plant and microbial controls over CZ function are lost. This results in nutrient cycling and rock weathering rates declining, and soil erosion rates increasing. 
4. The understanding developed on the processes controlling ecosystem productivity in the $\mathrm{CZ}$ is critical to identifying optimal management strategies for landscape regeneration. Through improving understanding of the biological and physical CZ processes, we hypothesise that it will be possible to identify areas where ecosystem restoration can be achieved, the management strategies for achieving this, and key plant species that can promote recovery of ecosystem services.

\section{Study site and methods}

The study catchment (Fig. 1) is a small basin $\left(1.29 \mathrm{~km}^{2}\right)$ located within Puding County, Guizhou Province, and is known as Chenqi $\left(26^{\circ} 15^{\prime} 36^{\prime \prime} \mathrm{N}, 26^{\circ} 15^{\prime} 36^{\prime \prime} \mathrm{E}\right)$. It contains a closed karst depression surrounded by four hills, with a dominant geology being limestone of the Guanling Formation of the Middle Triassic. The catchment elevation ranges between 1310 and $1470 \mathrm{~m}$ above sea level. The studied area has a sub-tropical monsoonal climate with an annual precipitation of $1300 \mathrm{~mm}$, with rainfall mainly occurring between May and October (Peng and Wang 2012). The temperature ranges from -1 to $28{ }^{\circ} \mathrm{C}$, with an annual average of $15.1{ }^{\circ} \mathrm{C}$ (Wang et al. 2014). The vegetation in the catchment is mainly broad-leaved deciduous shrubs and evergreens, with agriculture fields (e.g., corn, soybeans, and rape oil seed crops) located from mountain slope side to valley floor (Figs. 1, 2).

Twenty-seven soil profiles were exposed and each horizon in each soil profile was sampled. All horizon samples were analyzed for total carbon (TC), soil organic carbon (SOC) and total inorganic carbon (TIC). Additional higher-resolution depth-incremental samples were

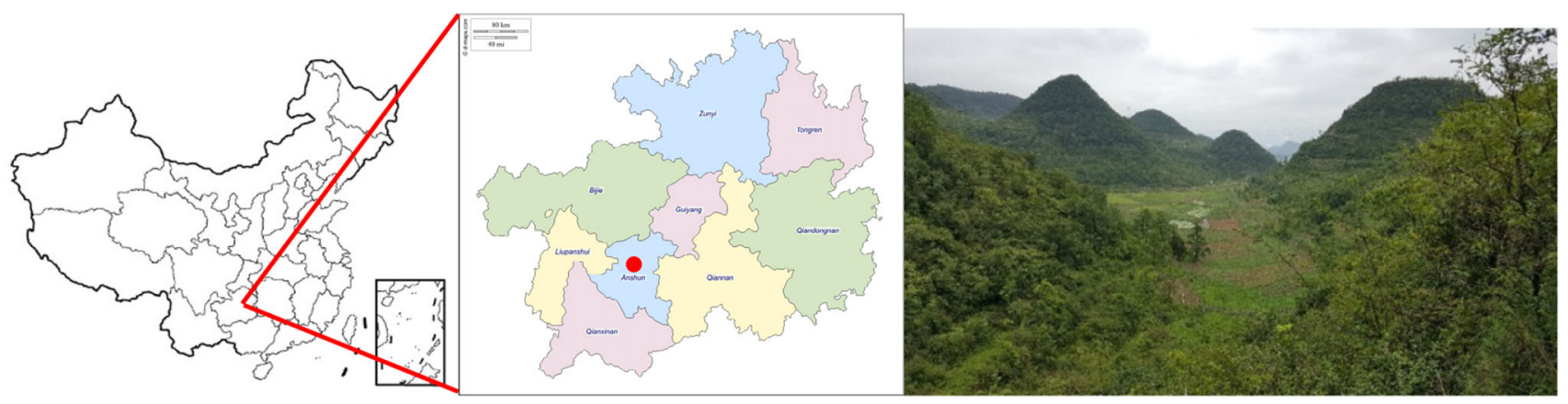

Fig. 1 Location of Chenqi, Guizhou, Southwest China and oblique view over the catchment

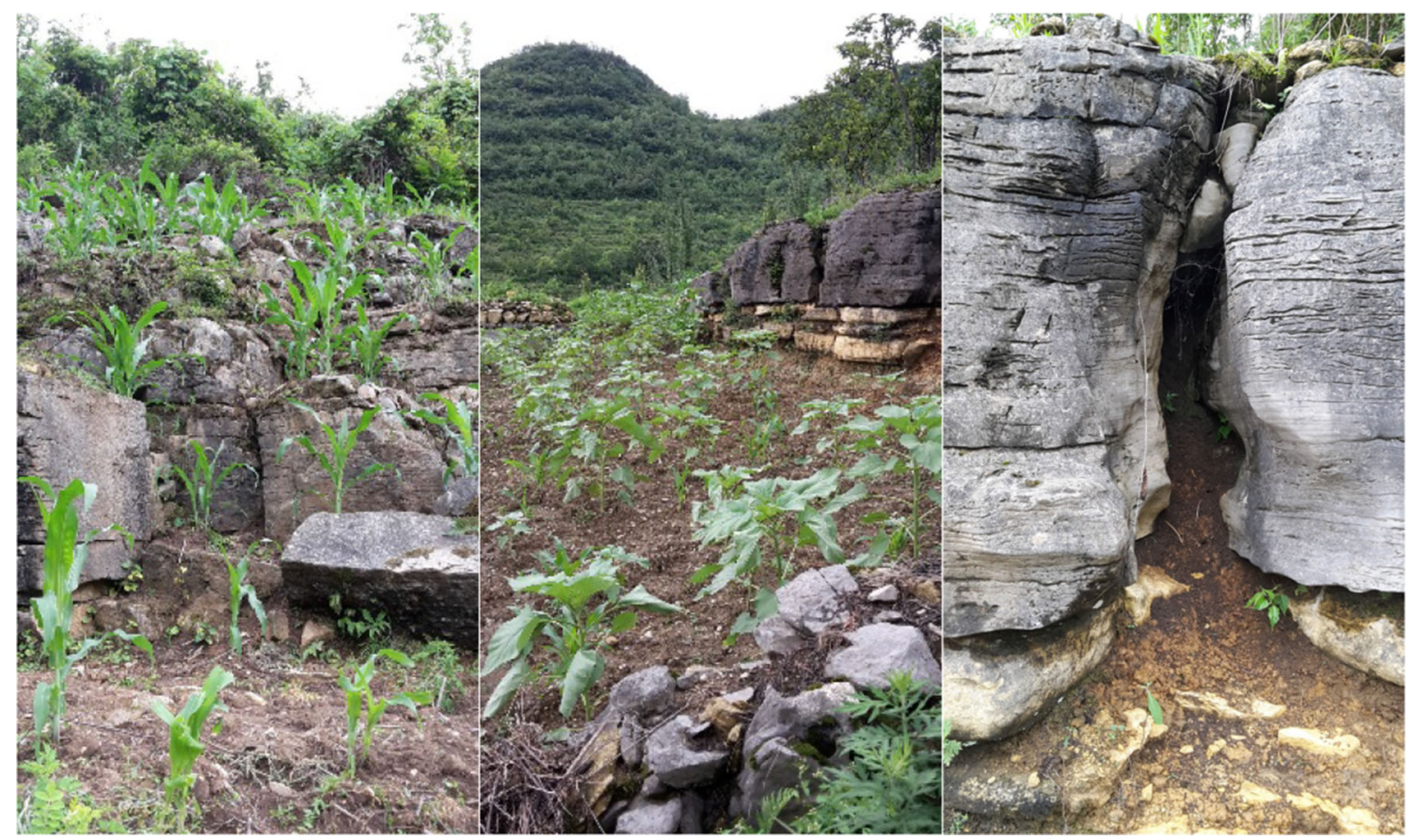

Fig. 2 The challenging terrain results in exploitation of pockets of soil as basement rock is exposed at the surface. Fissures in the limestone provide pathways for erosive runoff 
(a)

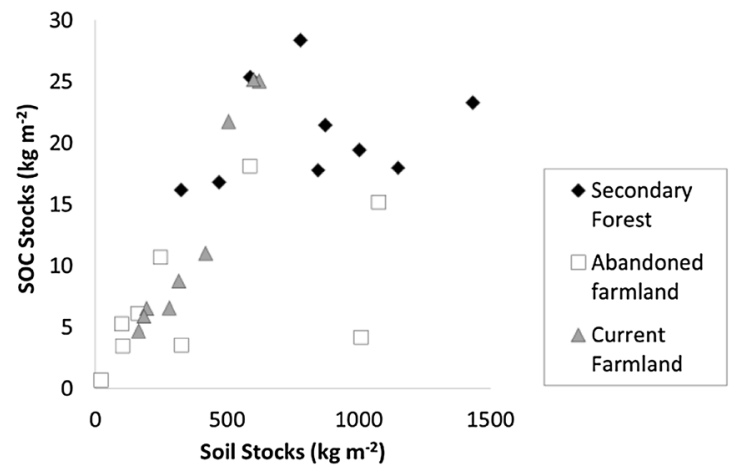

(b)

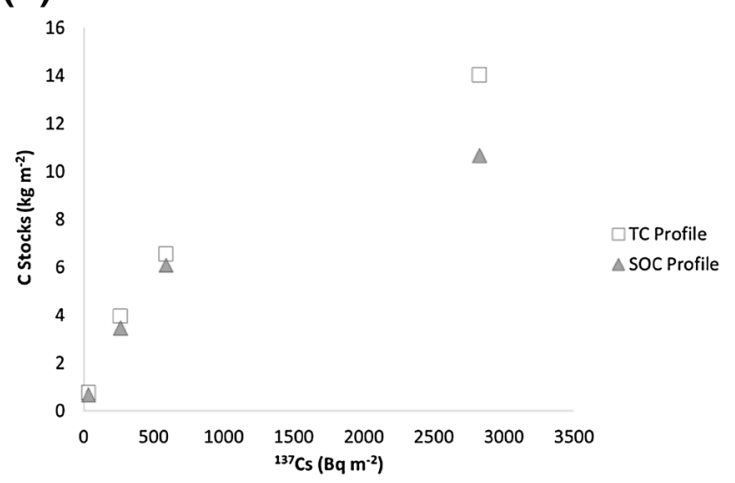

Fig. 3 Preliminary data from soil survey in Chenqi catchment: a variation in soil organic carbon (SOC) stocks with total soil stocks for three land use classes; b variation in SOC and total Carbon stocks with ${ }^{137} \mathrm{Cs}$ inventory in profiles from abandoned farmland

collected in order to derive depth profiles of caesium-137 $\left({ }^{137} \mathrm{Cs}\right)$ in order that this tracer can be used to derive quantitative assessment of soil redistribution and loss (cf Walling and Quine 1993; Quine and Van Oost 2007). Caesium-137 was measured by gamma spectrometry using a low background, closed end coaxial HPGe ORTEC gamma radiation detector. Count times were ca. $86400 \mathrm{~s}$. The depth distribution of ${ }^{137} \mathrm{Cs}$ activity per unit mass and the total inventory (activity per unit area) in each profile is used to interpret erosion history.

\section{Preliminary results}

Preliminary soil profile data collected from Chenqi show an expected decline in SOC content with depth, with horizon $\mathrm{A}\left(40.0 \pm 2.4 \mathrm{~g} \mathrm{~kg}^{-1}\right)=\mathrm{B}\left(31.8 \pm 3.4 \mathrm{~g} \mathrm{~kg}^{-1}\right)$ $>\mathrm{C} \quad\left(13.6 \pm 5.0 \mathrm{~g} \mathrm{~kg}^{-1}\right) \quad( \pm$ standard error $)$. In broad terms, all three horizons are seen in most of the soil profiles under secondary forest, where the A-horizon accounted for $7-60 \%$ of the soil stock (mass per unit area above bedrock). In contrast, in all but 3 (of 18) of the profiles on the current and abandoned farmland, the $\mathrm{C}$ horizon was absent and 11 (of 18) profiles the A horizon immediately overlay bedrock. This may reflect the pedogenic development of $\mathrm{A}$ horizon characteristics in eroded and depleted soils on these land use types. The individual profile data (Fig. 3a) suggest that SOC stocks on current farmland are strongly controlled by total soil stocks, reflecting relatively little variation in soil SOC content per unit mass. In contrast, on abandoned farmland and in secondary forest, total soil stock exerts less strong influence on SOC stocks. It is too early to establish the control of erosion on these patterns; however, very preliminary data (Fig. 3b) for abandoned fields are consistent with low SOC stocks in the most eroded (low ${ }^{137} \mathrm{Cs}$ ) soil profiles. Nevertheless, it is important to recognize that this pattern may not be present when a more complete dataset is available.

\section{Conclusions}

The SPECTRA CZO in Chenqi catchment, Guizhou Province, China is ideally suited to the investigation of the resilience and recovery of Karst ecosystems subject to intense anthropogenic perturbation. Ongoing research in the CZO will address: the constraints on plant productivity exercised by the heterogeneous nutrient-poor soil stocks; the disproportionate (with respect to prevalence) importance of silicate rocks in the control of ecosystem productivity; the potential to identify when the Karst ecosystem is approaching a tipping point in total soil storage and soil carrying capacity; and the use of understanding of processes controlling ecosystem productivity to identify optimal management strategies for landscape regeneration.

Acknowledgements This work was supported by the National Environmental Research Council of the UK (Grant No. NE/N007603/ 1) and the National Science Foundation of China (Grant Nos. 41571130042 and 41571130041).

Open Access This article is distributed under the terms of the Creative Commons Attribution 4.0 International License (http://creative commons.org/licenses/by/4.0/), which permits unrestricted use, distribution, and reproduction in any medium, provided you give appropriate credit to the original author(s) and the source, provide a link to the Creative Commons license, and indicate if changes were made.

\section{References}

Gao J, Xue Y, Wu S (2013) Potential impacts on regional climate due to land degradation in the Guizhou Karst Plateau of China. Environ Res Lett 8(4):044037

Heckrath G, Djurhuus J, Quine TA, Van Oost K, Govers G, Zhang Y (2005) Tillage erosion and its effect on soil properties and crop yield in Denmark. J Environ Qual 34:312-324

Huang QH, Cai YL (2007) Spatial pattern of karst rock desertification in the middle of Guizhou Province, southwestern China. Environ Geol 52:1325-1330 
Le Bissonnais Y, Arrouays D (1997) Aggregate stability and assessment of soil crustability and erodibility: II. Application to humic loamy soils with various organic carbon contents. Eur J Soil Sci 48(1):39-48

Li Y, Quine TA, Yu HQ, Govers G, Six J, Gong DZ, Wang Z, Zhang YZ, Van Oost K (2015) Sustained high magnitude erosional forcing generates an organic carbon sink: test and implications in the Loess Plateau, China. Earth Planet Sci Lett 411:281-289

Montgomery DR (2007) Soil erosion and agricultural sustainability. Proc Nat Acad Sci U. S. A. 104(33):13268-13272. doi:10.1073/ pnas.0611508104

Peng T, Wang S-j (2012) Effects of land use, land cover and rainfall regimes on the surface runoff and soil loss on karst slopes in southwest China. Catena 90:53-62

Quine TA, Van Oost K (2007) Quantifying carbon sequestration as a result of soil erosion and deposition: retrospective assessment using caesium-137 and carbon inventories. Glob Change Biol 13(12):2610-2625
Turner BL, Lambers H, Condron LM, Cramer MD, Leake JR, Richardson AE, Smith SE (2013) Soil microbial biomass and the fate of phosphorus during long-term ecosystem development. Plant Soil 367(1-2):225-234

Van Oost K et al (2007) The impact of agricultural soil erosion on the global carbon cycle. Science 318(5850):626-629

Walling DE, Quine TA (1993) Use of caesium-137 as a tracer of erosion and sedimentation: handbook for the application of the caesium-137 technique. Department of Geography, University of Exeter

Wang SJ, Liu QM, Zhang DF (2004) Karst rocky desertification in southwestern China: geomorphology, landuse, impact and rehabilitation. Land Degrad Dev 15:115-121

Wang J, Zou B, Liu Y, Tang Y, Zhang X, Yang P (2014) Erosioncreep-collapse mechanism of underground soil loss for the karst rocky desertification in Chenqi village, Puding county, Guizhou, China. Environ Earth Sci 72:2751-2764 